\title{
МЕХАНИЗМЫ ПАМЯТИ ПСИХОЛОГИЧЕСКОГО СТРЕССА И ВОЗДЕЙСТВИЯ НА НИХ В ЛЕЧЕНИИ СИНДРОМА ПОСТТРАВМАТИЧЕСКОГО СТРЕССА И БОЛЬШОГО ДЕПРЕССИВНОГО РАССТРОЙСТВА
}

При воздействии стресса на субъекта в одних случаях он приспосабливается и избегает негативных последствий стресса; у других субъектов в этих условиях развивается синдром посттравматического стресса (СПТС) или даже большое депрессивное расстройство (БДР). Во влиянии стресса на организм необходимо выделить его физические и психологические компоненты. В отличие от физического психологический стресс должен обладать такими качествами как неизбегаемость и/или неконтролируемость и способностью вызывать изменения поведения и когнитивных процессов (образ мыслей, обучение, память и др.). Представляется, что воздействие психологического стресса на когнитивные процессы, особенно в случае если стресс неконтролируемый, приводит к формированию неблагоприятной стратегии поведения в виде выученной беспомощности или иммобилизации, а также к негативной эмоциональной оценке всех воспроизводимых в памяти образов и событий $[1,2]$.

Избыточная генерализация памяти страха, порожденного угрожающей жизни ситуацией, лежит в основе СПТС. Страдающие этим заболеванием не могут предотвратить развитие обусловленных страхом негативных эмоциональных состояний, которые возникают при воздействии даже безвредных психологических стимулов в обычной не угрожающей жизни ситуации [3]. При воздействии на субъекта травматизирующей ситуации в остром периоде невозможно отличить СПТС от большого депрессивного расстройства, но чаще БДР возникает не сразу, а через длительный промежуток после травмы [4].

Как формируется, хранится и воспроизводится память стрессогенного воздействия, приводящего к нарушениям поведения и даже заболеваниям? Эта проблема интенсивно разрабатывается в последние два десятилетия. Наиболее ранние процессы формирования памяти стресса - изменения синаптической пластич- ности в лимбических структурах. Так, при воздействии острого неизбегаемого стресса в гиппокампе грызунов наблюдали угнетение экспрессии длительной потенциации (ДП), но облегчение развития длительной депрессии (ДД) синаптической передачи, причем последняя играет существенную роль в формировании БДР $[5,6]$. На проблему нарушения синаптической пластичности при стрессогенных воздействиях проливают свет данные, полученные исследователями из КНР. Они обнаружили, что при воздействии на крыс не избегаемого плавательного стресса в синапсах пирамидных нейронов области СА1 гиппокампа формируется статусиндуцируемая ДП синаптической передачи, которая возникает через 1 час после прекращения не избегаемого плавания, длится до 4 часов и сопровождается увеличением времени иммобилизации крыс при последующих воздействиях неизбегаемого плавания в промежуток времени от 2 до 24 часов. В основе этой формы ДП лежит фосфорилирование остатка серина в 831-й позиции (Cep831) в структуре GluA1 субъединицы глутамтных рецепторов, активируемых помимо глутамата $\alpha$-амино-3-гидрокси5-метил-4-изоксазолпропионовой кислотой (АМРА). Фосфорилирование рецепторов, приводящее к повышению их плотности в постсинаптической мембране, осуществляется с помощью $\mathrm{Ca} /$ кальмодулин-зависимой протеинкиназы II (CaMKII). Как ДП синаптической передачи, так и увеличение времени иммобилизации при последующих воздействиях не избегаемого стресса предотвращаются блокаторами НМДА глутаматных и глюкокортикоидных рецепторов, а также электрической стимуляцией через отводящие электроды области СА1. В тоже время, у крыс, которые могли избавляться от стрессоген-

(с) И.И. Абрамец, Д.В. Евдокимов, Ю.В. Кузнецов, Ю.В. Сидорова, 2020

(c) Университетская Клиника, 2020 
ной ситуации, наблюдали типичную реакцию на стресс (рост уровня кортикостерона, увеличение количества дефекаций и др.), но не наблюдали ни ДП синаптической передачи, ни увеличения продолжительности иммобилизации [7]. Авторы оценивают эту стресс-индуцируемую форму ДП как гиппокампальную энграму «памяти отчаяния» (despair memory), которая со временем перемещается в префронтальную кору (генерализация) и при последующих воздействия воспроизводится и меняет поведение - увеличивая время иммобилизации. При повторных воздействиях не избегаемого стресса продолжительность сохранения памяти отчаяния существенным образом возрастает. Так при повторных воздействиях не избегаемого плавательного стресса в течение 5 дней продолжительность увеличения времени иммобилизации при последующих воздействиях стресса возрастало до 1 месяца [8].

В соответствии с законами метапластичности в потенцированных синапсах затруднена дальнейшая экспрессия ДП, но облегчается развитие ДД синаптической передачи [9], что наблюдается при моделировании на животных депрессивного фенотипа поведения и у больных БДР. В тоже время, локусы и механизмы последующих консолидации и воспроизведения памяти отчаяния остаются не выясненными. В определенной степени эта проблема разработана для памяти страха (fearmemory), играющей важную роль в развитии СПТС.

Память свежих недавних событий непродолжительное время хранится в системе гиппокамп-медиальная энторинальная кора и затем медленно перемещается, и консолидируется в префронтальной коре для постоянного хранения (отдаленная память) $[10,11]$. Процедура формирования контекстуального условного страха (КУС) в первую очередь вызывает пластические перестройки синапсов энграмных нейронов гиппокампа в форме ДП синаптической передачи. Далее информация передается на энграмные нейроны 5а слоя медиальной энторинальной коры (МЭК), откуда информация распространяется параллельными потоками в базолатеральное ядро миндалины (БЛМ) и префронтальную кору (ПФК). Незрелые энграмы памяти в ПФК формируются в 1-й день тренировки через входы от МЭК и БЛМ и затем в течение нескольких недель происходит их созревание, т. е. трансформация в энграмы отдаленной памяти. Энграмные клетки БЛМ, изменяющие активность во время тренировки, участвуют в воспроизведении ранней и отдаленной памяти. Имеются данные, что источник поступления информации к энграмам БЛМ в про- цессе воспроизведения может перемещаться от МЭК в ранние сроки к энграмам ПФК в более отдаленные сроки. Источник активации контекстуальными стимулами зрелых энграм ПФК не известен. Полагают, что источником активации может быть таламус, поскольку энграмные нейроны ПФК получают моносинаптические входы от медиодорсального и антеромедиального ядер таламуса. Что касается энграмных клеток гиппокампа, то они быстро переходят в «молчащее» состояние, утрачивают информацию исходной памяти и могут участвовать в отдаленном воспоминании отдельных эпизодических деталей [12].

Имеются данные, согласно которым память условного страха сохраняется у грызунов на протяжении длительного времени до 480 дней при продолжительности жизни до 700-750 дней [13]. Причины столь длительного сохранения памяти условного страха окончательно не выяснены. Считают, что активация энграм старой памяти и последующая их реконсолидация приводят к непрерывному обновлению и сохранению памяти [14]. Но при этом не ясно, действительно ли реконсолидированная память идентична первичной памяти или между ними есть качественные различия. Процесс консолидации первичной памяти связан с активацией некоторых ранних генов - C/EBP, cFos, Zif268 и эффекторных генов Arc, TPA [15, 16]. На системном уровне процесс заканчивается переносом лабильной памяти из гиппокампа в стабильную память в префронтальной коре. Накапливаются данные о том, что процессы реконсолидации памяти после повторной ее активации и воспроизведения отличаются от процессов первичной консолидации памяти. Установлено, что экспрессия транскрипционного фактора C/EBP в миндалине необходима для процесса консолидации, а усиление трансляции белка там же необходима для консолидации и реконсолидации. Процесс реконсолидации вкусовой аверсии сопровождался накоплением нейротрофинаBDNF в инсулярной коре, но не в центральном ядре миндалины, а при консолидации нейротрофин накапливался в обеих структурах. Локальное угнетение трансляции белка в миндалине нарушало консолидацию, но не реконсолидацию памяти. Наконец, установлено, что усиление биосинтеза белка в прилежащем ядре необходимо для консолидации, но не реконсолидации памяти [17].

Считают, что хранилищами памяти являются возбуждающие глутаматергические синапсы и дендритные шипики, как их составная часть. Морфологически различают 4 типа шипиков: филоподии, короткие (похожие на пенек), тонкие и зрелые грибовидные шипики. Общепри- 
нято, что тонкие шипики - это шипики обучения, т. е. локусы формирования будущей памяти, а зрелые грибовидные шипики, несущие синапсы больших размера и мощности, ответственны за формирование нейронных сетей и долгосрочной памяти. Грибовидные шипики содержат гладкий эндоплазматический ретикулум, полирибосомный и эндосомальный компартменты; в этих шипиках может осуществляться локальный синтез белков, их посттрансляционная модификация, локальный рециклинг рецепторов и белков постсинаптического уплотнения $[18,19]$. Короткие и тонкие шипики более чувствительны, а грибовидные шипики более устойчивы к разнообразным повреждающим воздействиям, в частности, к действию стресса и гормонов стресса.

Воспоминание, т. е. реактивация памяти дестабилизирует уже консолидированную память и последующая ее реконсолидация требует экспрессии ряда генов. Ранний ген Arc участвует в консолидации синаптической пластичности (ДП) и долгосрочной памяти. Экспрессия этого гена наблюдается вскоре после первичного обучения и воспроизведения памяти и необходима для ранней стабилизации вновь сформировавшейся и реактивированной памяти. Установлено, что процедура выработки КУС вызывала повышение уровня Arc в БЛМ через 2 и 12 часов после тренировки; в промежутке между этими сроками и через 24 часа уровень Arc не отличался от исходного. Угнетение поздней фазы (12 часов) экспрессии Arc нарушало сохранение памяти при ее тестировании через 7, но не 2 дня [20].

Дестабилизация реактивированной памяти условного страха связывают с активаций содержащих NR2B субъединицу глутаматных рецепторов, активируемых помимо глутамата $\mathrm{N}$-метилD-аспартатом (НМДА), в мембранах пирамидных нейронов БЛМ, а рестабилизацию памяти связывают с поздней (12 часов) экспрессией Arc. Блокада НМДА глутаматных рецепторов ифенпродилом перед воспроизведением памяти препятствует поздней экспрессии гена $\operatorname{Arc}$ и препятствует сохранению памяти. Следовательно, активация содержащих NR2B субъединицу НМДА рецепторов при воспроизведении памяти запускает ее дестабилизацию, которая влечет за собой раннюю стабилизацию и последующую сохранность памяти [20]. Причина дестабилизации памяти - разрушение белков цитоскелета в дендритных шипиках, обусловленное опосредуемым НМДА рецепторами ростом активности CaMKII, которая привлекает в шипики протеосомы $[21,22]$. С другой стороны, активация содержащих NR2B субъединицу НMДА рецепторов вызывает ап-регуляцию нейрональной синтазы оксида азота (NOS), которая эпигенетически повышает уровень гена Arc, способствующего сохранности памяти [23].

В консолидациии реконсолидации памяти КУС существенную роль играет ДД синаптической передачи в гиппокампе. На синаптическом уровне выявлено усиление эндоцитоза и снижение плотности содержащих GluA2 субъединицу АМРА рецепторов в постсинаптической мембране и уменьшение объема дендритных шипиков [24]. У мышей с генным нокаутом апоптотического белка Вах, который необходим для развития этой формы синаптической пластичности, наблюдали угнетение развития ДД синаптической передачи в гиппокампе и проявлений контекстуального условного страха. Интересно, что у этих же мышей выявили сниженный уровень депрессивности [25]. Возможный механизм, с помощью которого поздняя экспрессия Arc облегчает сохранность памяти - оптимизация нейронной сети за счет сморщивания дендритных шипиков. Хотя следы памяти формируются путем усиления синаптических связей, элиминация избыточных синапсов повышает качество функциональной системы памяти.

Консолидация, воспроизведение и реконсолидация памяти условного страха регулируется отделом ПФК - прелимбической корой. Так, повышение активности ее нейронов фармакологическим путем облегчало консолидацию, воспроизведение и реконсолидацию памяти условного страха даже в условиях подпороговой интенсивности вызывающих эту память процедур. Более того, при повышении активности прелимбической коры усиливалась генерализация страха и нарушалось обучение угашению [26]. С другой стороны, при выработке и первичной консолидации памяти КУС наблюдали угнетение активности пирамидных нейронов $2 / 3$ и 5 слоев другого отдела ПФК -инфралимбической коры, которое проявлялось угнетением генерации спайков и увеличением амплитуд медленной послеспайковой гиперполяризации (sАНР) [27].

Наряду с медленным разрушением памяти существует процедура относительно быстрого угашения (extinction) памяти условного страха. Процедура угашения осуществляется повторной презентацией условного стимула или контекста в отсутствие воздействия безусловного аверсивного стимула. Считают, что в процессе угашения памяти условного страха образуется новая форма памяти безопасности, которая угнетает воспроизведение памяти страха, но не разрушает исходную память условного страха. Ослабленный процедурой угашения условный страх может спонтанно восстанавливаться через некоторое время или возобновляться в случае пре- 
зентации условного стимула вне контекста угашения [28]. Следовательно, память условного страха и угашения - это две разные формы памяти, причем первая память более стабильна и хранится дольше. В процессе выработки условного страха наблюдали увеличение плотности дендритных шипиков пирамидных нейронов области CA1 дорсального гиппокампа. Воспроизведение угашения условного страха сопровождалось снижением плотности дендритных шипиков до уровня интактных животных. Воздействие стресса сопровождалось угнетением обучения угашения, что обусловлено отсутствием влияния процедуры угашения в этих условиях на плотность дендритных шипиков [29]. Процедура угашения условного страха сопровождалсь повышением возбудимости пирамидных нейронов инфралимбической коры, угнетением медленной послеспайковой гиперполяризациии облегчением развития ДП синаптической передачи [27].

В тоже время, некоторые элементы памяти условного страха могут изменяться с течением времени в результате процесса генерализации. Генерализацию определяют как реакцию на стимулы, похожие на те, которые вызывали формирование памяти, и рассматривают как разновидность забывания, считают активным памятным процессом необходимым для поведенческой гибкости и фундаментальным свойством обучения и памяти [30]. Генерализация становится более интенсивной при увеличении промежутка времени между тренировкой и тестированием. В памяти условного страха можно выделить два компонента - контекстуальный (гиппокамп-зависимый) и сигнальный (гиппокамп-независимый) и оба эти компонента кодируются и хранятся разными нейронными сетями. Контекстуальная память условного страха формируется очень быстро, а генерализация - медленно в течение более 24 часов. Генерализация, но не сама память повреждается при угнетении синаптических связей между ипси- и контрлатеральным отделами области СА1 дорсального гиппокампа. По мере развития генерализации в пирамидных нейронах этих отделов гиппокампа возрастает амплитуда синаптических потенциалов, а при угнетении генерализации эта форма синаптической пластичности не реализуется. Прямое возбуждение синапсов пирамидных нейронов, образованных связями между левым и правым отделами гиппокампа облегчает формирование генерализации. Таким образом, генерализация контекста - активный процесс, зависимый от билатеральных СА1 областей и кодируемый в этих областях [31]. Генерализация сигнального компонента памя- ти условного страха развивается более медленно в течение нескольких недель и реализуется в других нейронных ансамблях. Генерализация сопровождается изменениями синаптической пластичности, а именно повышением синаптической активности в БЛМ и в прелимбической коре, но снижением синаптической активности в агранулярной инсулярной и инфралимбической коре [32].

Память об опасных явлениях и местах имеет особое значение поскольку она подвержена генерализации. В окружающей среде, в которой сигналы о появлении опасности неоднозначны, ложная тревога (генерализация)может быть адаптивным достижением, а не недостатком. Однако избыточная генерализация травматического страха неблагоприятна для субъекта и является мишенью терапевтического воздействия при СПТС и тревожных расстройствах [33]. Исследования на грызунах генерализации сигнальной слуховой памяти страха могут способствовать нашему пониманию травматического фенотипа, как комбинации отдельных элементов памяти травматического страха - сигнального (выходящего на передний план) и контекстуального (фонового) [34]. Больные ПТСР не способны ограничить экспрессию страха на воздействие не имеющих отношения к травме безвредных стимулов.

Один из способов лечения ПТСР - когнитивная терапия, базирующаяся на процедуре угашения, когда травматические воспоминания воспроизводятся в безопасной обстановке и приводят к прогрессивному уменьшению экспрессии страха. Однако с течением времени травматический страх восстанавливается, поскольку процедура угашения не разрушает память страха.

Помимо когнитивной терапии и особенно совместно с ней для лечения СПТС широко используются антидепрессанты, особенно селективные ингибиторы обратного захвата серотонина. Основная цель совместной когнитивной и фармакотерапии - предотвращение спонтанного восстановления памяти страха после процедуры угашения. В исследованиях на крысах установлено, что хроническое введение флуоксетина усиливает угашение контекстуальной памяти страха и длительное ослабление страха достигается тогда, когда флуоксетин начинают вводить после тренировки угашения. Следовательно, угнетение памяти страха может быть достигнуто двумя путями: усилением угашения страха за счет ослабления генерализации памяти страха и предотвращением спонтанного восстановления страха после угашения [35].

В процессе реконсолидации и генерализации память страха утрачивает связь с контекстом 
(становится гиппокамп-независимой) и перемещается в переднюю поясную кору. При этом происходят изменения синаптической пластичности в нейронах гиппокампа и неокортекса. Действительно, в пирамидных нейронах области CA1 гиппокампа наблюдали снижение плотности дендритных шипиков; напротив, в пирамидных нейронах 2/3 слоев передней поясной коры плотность дендритных шипиков возрастала [36, 37]. Реконсолидация и генерализация памяти условного страха ослабляются при угнетении секреции кортикостерона метирапоном и блокаде центральных бета-адренорецепторов пропранололом [38]. Хроническое введение флуоксетина приводило к увеличению плотности дендритных шипиков (особенно зрелых грибо-подобных) в пирамидных нейронах гиппокампаи это сопровождалось угнетением генерализации памяти страха и восстановлением ее связи с контекстом [35]. Эффекты флуоксетина связаны с его модулирующим влиянием на нейрогенез в зубчатой извилине, синаптическую пластичность и ремоделирование дендритных шипиков в пирамидных и зернистых нейронах гиппокампа. Влияние данного антидепрессанта на проявления БДР (нормализация настроения, ослабление ангедонии) как и влияние на условный страх обусловлено ремоделированием дендритных шипиков в гиппокампе [39]. Это позволяет думать, что память условного страха и вызываемая не избегаемым стрессом память «отчаяния» перекрываются лишь частично. В тоже время, имеются данные, согласно которым формирование и консолидация этих форм памяти осуществляется энграмными нейронами в разных участках лимбической системы. Действительно, при воздействии на животных интенсивного стресса у $47 \%$ животных развивался тревожный, а у 15\% - тревожно-депрессивный (ангедонический) фенотип поведения. Для первого фенотипа характерно повышение активности нейронов БЛМ, дорсальной области САЗгиппокампа, всех слоев вентрального гиппокампа, сердцевины прилежащего ядра и всех отделов серого вещества периакведукта; для ангедонического фенотипа изменения выявлены в инфралимбической коре, центральном ядре и БЛМ, вентральной зубчатой извилине, в раковине прилежащего ядра и во всех отделах периакведукта [40].

Имеются указания на то, что СПТС и БДР имеют различные не совпадающие нейрофизиологические и нейрохимические маркеры. Действительно, для СПТС, но не БДР характерны гипертензия и низкий уровень кортизола. После введения кортизола воспроизведение памяти усилено у больных СПТС, а при БДР оно не меня- ется [41]. Представляется, что СПТС может развиваться после однократного воздействия угрожающей жизни ситуации; иногда подобное воздействие способствует развитию БДР, но гораздо чаше заболевание возникает при условии накопления в памяти прошлых стрессогенных во3действий. Т. е. механизмы консолидации и воспроизведения прошлой памяти не избегаемого стресса существенны для развития депрессии.

Для БДР характерно нарушение функциональной активности системы самооценки (defaultmodesystem) и особенно ее ключевой структуры субгенуальной передней поясной коры (сППК). Эта система позволяет субъекту оценивать свое внутреннее, в том числе и эмоциональное состояние. При выполнении когнитивных заданий активность системы самооценки угнетается. При БДР выявлено повышение активности сППК, которая наряду с некоторыми подкорковыми структурами осуществляет обработку аверсивной, эмоционально негативной информации [42]. В связи с этим у больных БДР наблюдаются повторяющиеся навязчивые размышления (rumination) о депрессивных симптомах, их причинах и последствиях. Появление и возрастание этих размышлений предшествует началу депрессии, развитию более выраженной депрессивной симптоматики и неблагоприятным последствиям [43].

Следствием этого являются нарушения эмоциональной оценки окружающей действительности. Так нейтральные события или лица воспринимаются больными как печальные, т. е. оценка автоматически определяется негативным мышлением, которое базируется на основе памяти пережитого ранее психологического стресса. Кодирование и воспроизведение определенных неблагоприятных условий ведут к специфическим воспоминаниям в результате генерализации воспоминаний. Как отмечалось ранее, генерализация памяти - активный процесс, дополняющий ресурсы памяти и позволяющий переносить негативную эмоциональную информацию из одной памяти в другую. В клинических условиях установлено, что у больных БДР наблюдается избыточная генерализация негативной памяти [44]. Быстрая форма генерализации памяти при воздействии различных сигналов способствует воспроизведению отрицательных эмоций, которые связаны с памятью ранее пережитого психологического стресса [31] и автоматически определяют негативный стиль мышления. В этом плане представляют интерес результаты исследований, в которых установлено, что на фоне стресс-индуцируемого депрессивно-подобного поведения в дендритах пирамидных нейронов области CA1 гиппо- 
кампа и мПФК грызунов снижена плотность коротких и тонких дендритных шипиков, а количество грибовидных шипиков не меняется [45, 46]. Таким образом, при моделировании депрессивного фенотипа у грызунов и у больных БДР старая память пережитого социального стресса, хранящаяся в грибовидных шипиках, стабильно сохраняется и воспроизводится. В тоже время, из-за снижения плотности тонких шипиков обучения возможность формирования новой позитивной или даже нейтральной памяти, конкурирующей с негативной памятью социального стресса, существенно ограничена.

Важный вопрос - в каком состоянии находятся энграмные клетки памяти психологического стресса: в возбужденном или угнетенном, поскольку это важно для предотвращения или устранения симптомов БДР. При воздействии хронического не избегаемого плавательного стресса выявлено повышение возбудимости пирамидных нейронов $2 / 3$ слоев передней поясной коры у крыс на фоне депрессивноподобного поведения [8]. Как отмечалось ранее, при тревожно-депрессивном фенотипе у грызунов наблюдали повышение активности нейронов инфралимбической коры, БЛМ, раковины прилежащего ядра [40]. Представления о повышенной возбудимости лимбических нейронов подкрепляются также тем, что блокатор НМДА глутаматных рецепторов кетамин обнаруживает быстрое и длящееся до недели антидепрессивное действие у больных БДР и при моделировании этого заболевания у грызунов. Этому, однако, противоречит то, что кетамин повышает активность АМРА глутаматных рецепторов и усиливает образование новых синапсов [47]. Помимо этого, установлено, что агонист ванилоидных рецепторов I типа капсаицин, который возбуждает центральные нейроны, ослабляет вызываемые стрессом нарушения синаптической пластичности и пространственной памяти [48]. Общее впечатление таково, что при БДР существенно повышена активность вентральных (аффективных) отделов лимбической системы, в то время как активность когнитивных, оценочных дорсальных кортикальных структур понижена [49].

После введения кетамина в дозе 5 мг/кг в области CA1 гиппокампа бодрствующих подвижных крыс выявлено развитие ДД синаптической передачи и это нарушало воспроизведение пространственной памяти. В этих же условиях кетамин вызывал гиперлокомоцию, угнетение внутреннего торможения и социальное отторжение. Синаптические и поведенческие эффекты кетамина устранялись блокаторами Д1/Д5 дофаминовых рецепторов и ингибиторомэндоци- тоза AMРА рецепторов. Помимо этого, кетаминугнетал развитие ДП синаптической передачи в среднешипиковых нейронах сердцевины прилежащего ядра, препятствовал фосфорилированиюСер831 в структуре GluA1 субъединицы AMPА рецепторов и вызывал ДД синаптической передачи в дофаминергических нейронах вентральной тегментальной области [50]. Эти факты указывают на то, что кетамин в субанестетических дозах вызывает у интактных животных психотические нарушения подобные шизофрении. С другой стороны, в исследованиях на срезах гиппокампа грызунов установлено, что воздействие кетамина в субанестетических дозах (5-25 мкM) вызывало развитие ДП синаптической передачи в пирамидных нейронах области CA1, обусловленной как повышением плотности постсинаптических содержащих GluA1 субъединицу AMPА глутаматных рецепторов, так и усилением пресинаптического высвобождения глутамата $[51,52]$. Через 24 часа после системного введения кетамина в срезах префронтальной коры мышей наблюдали увеличение частоты спонтанных миниатюрных (м) ВПСП пирамидных нейронов 2/3 слоев, но снижение амплитуд мВПСП без изменения величин парного отношения; при введении животным гормона стресса кортикостерона выявлено существенное угнетение частоты мВПСП пирамидных нейронов [53]. Полученные результаты авторы интерпретируют как свидетельство того, что кетамин, усиливая процессы трансляции белка в дендритах, способствует образованию и увеличивает количество незрелых синапсов, содержащих минимальное количество АМРА глутаматных рецепторов, в которых облегчено развитие ДП синаптической передачи (формирование энграм памяти). С другой стороны, основной гормон стресса угнетает синаптогенез и это сопровождается когнитивными нарушениями. Важно, что при системном введении кетамина грызунам на фоне депрессивного фенотипа препарат ослаблял проявления поведенческой депрессии. По-видимому, влияние кетамина при моделировании депрессивно-подобного поведения может отличаться от его влияния на интактных животных.

Быстрый терапевтический эффект, как и при применении кетамина, также развивается при лечении больных БДР электросудорожной терапией (ЭСТ). ЭСТ вызывает амнезию у больных и нарушает память у животных. Другая антидепрессивная процедура - электрическая стимуляция мозга в области СА1гиппокампа у животных нарушает воспроизведение памяти не избегаемого стресса [7]. Кроме того, установлено, что оптогенетическая стимуляция этой же области 
гиппокампа инактивирует память страха [54]. Эти факты позволяют думать, что кетамин может вызывать угнетение воспроизведения памяти «отчаяния».

В результате процесса генерализации происходит многократное воспроизведение памяти не избегаемого психологического стресса. При этом можно думать, что эта память, подобно памяти условного страха, подвергается множественной реконсолидации. Как отмечалось ранее при повторном воспроизведении память страха становится нестабильной в связи с активацией содержащих NR2B субъединицу НМДА глутаматных рецепторов и это запускает процесс ее реконсолидации. С другой стороны, блокада NR2B HMДА глутаматных рецепторов препятствует реконсолидации старой памяти не избегаемого психологического стресса и вызывает ее ослабление. Подобно НМДА глутаматным рецепторам М-холинорецепторы энграмных нейронов участвуют в воспроизведении и реконсолидации памяти и также, как и кетамин, M-холиноблокаторы (скополамин) обладают быстрым антидепрессивным действием [55].

Помимо этого, кетамин, М-холиноблокаторы, блокаторы метаботропных глутаматных рецепторов 2/3 типов активируют сигнальный путь протеинкиназы mTOR и это сопровождается усилением процесса трансляции белков в дендритах, в частности синаптических белков - синапсина I, PSD-95, GluA1 субъединицы AMPA глутаматных рецепторов, образованием новых синапсов и повышением возбудимости нейронов. Важно, что эти эффекты не воспроизводятся на интактных животных, а наблюдаются при угнетении синаптической передачи в коре и гиппокампе при моделировании депрессивного фенотипа поведения [56, 57]. Вызываемое кетамином и другими быстродействующими антидепрессантами усиление синаптических функций способствует формированию новой либо нейтральной, либо позитивно окрашенной памяти вместо старой памяти психологического стресса. С другой стороны, временная блокада НМДА глутаматных или М-холинорецепторов в энграмных нейронах, а также усиление пресинаптического высвобождения глутамата блокаторами метаботропных глутаматных рецепторов 2/3 типов препятствуют реконсолидации старой памяти не избегаемого стресса. Тем не менее, представляется, что сформировавшаяся при действии кетамина и других быстрых антидепрессантов новая, по крайней мере, не несу- щая негативной информации память угнетает преимущественно воспроизведение старой памяти не избегаемого стресса и это обеспечивает улучшение эмоционального статуса при моделировании на животных депрессивного фенотипа поведения и у больных БДР.

Рассмотренная выше ситуация весьма близка к процессу угашения памяти условного страха, при котором изолированное воздействие безусловного раздражителя формирует новую память, которая конкурентно угнетает воспроизведение старой памяти условного страха. При депрессивном фенотипе поведения у грызунов и у больных БДР антидепрессанты быстрого действия создают предпосылки для формирования другой, лишенной негативной валентности памяти за счет формирования новых синапсов и повышения возбудимости энграмных нейронов. Эта новая память временно блокирует механизмы воспроизведения старой памяти неизбегаемого психологического стресса.

Но сформировавшаяся на фоне быстродействующих антидепрессантов новая память существует на протяжении меньшего промежутка времени по сравнению с памятью не избегаемого стресса, которая спонтанно восстанавливается по мере ослабления новой памяти. Повидимому, с этим связано непродолжительное (от нескольких дней до недели) действие быстрых антидепрессантов [55]. Можно думать, что продолжительность действия кетамина и других быстрых антидепрессантов определяется временем существования синаптических белков, трансляцию которых антидепрессанты усиливают. По существующим представлениям это время составляет несколько суток.

Несомненный практический интерес представляет увеличение продолжительности действия быстрых антидепрессантов. Поскольку их влияние на формирование новой памяти, конкурирующей с памятью не избегаемого психологического стресса, связано с процессами биосинтеза белка представляется возможным усилить и пролонгировать действие антидепрессантов церебропротекторами-ноотропами. Эта группа лекарственных средств усиливает биоэнергетические и биосинтетические процессы в нейронах. Реальность такой возможности подтверждается экспериментальными данными, согласно которым пирацетам усиливает влияние кетамина как на синаптические процессы в гиппокампе, так и на ослабление проявлений поведенческой депрессии [52]. 


\section{И.И. Абрамец, Д.В. Евдокимов, Ю.В. Кузнецов, Ю.В. Сидорова}

ГОО ВПО «Донецкий национальный медицинский университет имени М. Горького», Донецк

\section{МЕХАНИЗМЫ ПАМЯТИ ПСИХОЛОГИЧЕСКОГО СТРЕССА И ВОЗДЕЙСТВИЯ НА НИХ В ЛЕЧЕНИИ СИНДРОМА ПОСТТРАВМАТИЧЕСКОГО СТРЕССА И БОЛЬШОГО ДЕПРЕССИВНОГО РАССТРОЙСТВА}

Стресс, особенно его психологический компонент, связанный с невозможностью управлять им, или избежать его воздействия, вызывает тревожные или депрессивные расстройства в виде синдрома посттравматического стресса и большого депрессивного расстройства. В формировании этих заболеваний существенную роль играют формирование, воспроизведение и генерализация памяти страха и памяти отчаяния, которые нарушают деятельность синапсов, нейронов, нейронных сетей и поведения.В этом обзоре рассмотрены механизмы формирования и вос- произведения памяти контекстуального условного страха и отчасти памяти не избегаемого психологического стресса (памяти отчаяния). Проанализировано влияние традиционных и быстродействующих антидепрессантов на эти формы памяти, как одно из направлений фармакотерапии указанных аффективных расстройств.

Ключевые слова: психологический стресс, память, синдром посттравматического стресса, депрессия, антидепрессанты.

\section{I.I. Abramets, D.V. Evdokimov, Yu.V. Kuznetsov, Yu.V. Sidorova}

SEI HPE «M. Gorky Donetsk National Medical University», Donetsk

\section{THE MECHNISMS OF PSYCHOLOGICAL STRESS MEMORY AND ACTIONON THEM IN TREATMENT OF POSTTRAUMATIC STRESS AND MAJOR DEPRESSION DISORDERS}

Psychological component of stress bound with absence of possibility to control it or to escape of it action causes anxious or depression disorder in the manner of posttraumatic stress and major depression disorders. The acquisition, retrieval and generalization of fear memory and despair memory break activity of synapses, neurons, neuronal circuitries and behavior and play essential role in development of these disorders. In this review, the mechanisms of acquisition, consolidation, retrieval and reconsolidation of contextual conditioned fear memory and partialy despair memory (memory of inescapable psychological stress) are considered. An influence of traditional and fast acting antidepressants on these forms of memory was analyzed in review as one of directions of pharmacotherapy of these affective disorders.

Key words: psychological stress, memory, posttraumatic stress disorder, depression, antidepressants.

\section{ЛИТЕРАТУРА}

1. Martin E, Seligman P, Maier SF. Failure to escape traumatic shock. J Exp Psychol. 1967; 74 (1): 1-9. doi: 10.1037/ h0024514.

2. Bleys D, Luyten P, Soenens B, Claes S. Gene-environment interactionsbetween stress and 5-HTTLPR in depression: a meta-analytic update. J AffectDisord. 2018; 226: 339345. doi: 10.1016/j.jad.2017.09.050.

3. Kaczkurkin A N, et al. Neural substrates of overgeneralized conditioned fear in PTSD. Am J Psychiatry. 2017; 174 (2): 125-134. doi: 10.1176/appi.ajp.2016.15121549.

4. Odonnell M, Creamer M, Pattison P. Posttraumatic stress disorder and depression following trauma: understanding comorbidity. Am J Psychiatry. 2004;161 (8): 1390-1396. doi: 10.1176/appi.ajp.161.8.1390.

5. Kim JJ, Diamond DM. The stressed hippocampus, synaptic plasticity and lost memories. Nat Rev Neurosci.2002; 3(6): 453-462. doi: 10.1038/nrn849.

6. Duman RS, Aghajanian GK. Synaptic dysfunction in depression: potential therapeutic targets. Science. 2012; 338 (6103): 68-72. doi: 10.1126/science.1222939.

7. Jing L, Duan TT, Tian M, et al. Despair-associated memory requires a slow-onset CA1 long-term potentiationwith unique underlying mechanisms. Sci Rep.2015; 5: 15000. doi: $10.1038 /$ srep15000.

8. Sun P, Wang F, Wang L, et al. Increase in cortical pyramidal cell excitability accompanies depression-like behavior in mice: a transcranial magnetic stimulation study. J Neurosci; 2011; 31 (45): 16464 - 16472. doi: 10.1523/

\section{REFERENCES}

1. Martin E, Seligman P, Maier SF. Failure to escape traumatic shock. J Exp Psychol. 1967; 74 (1): 1-9. doi: 10.1037/ h0024514.

2. Bleys D, Luyten P, Soenens B, Claes S. Gene-environment interactionsbetween stress and 5-HTTLPR in depression: a meta-analytic update. J AffectDisord. 2018; 226: 339345. doi: 10.1016/j.jad.2017.09.050.

3. Kaczkurkin A N, et al. Neural substrates of overgeneralized conditioned fear in PTSD. Am J Psychiatry. 2017; 174 (2): 125-134. doi: 10.1176/appi.ajp.2016.15121549.

4. Odonnell M, Creamer M, Pattison P. Posttraumatic stress disorder and depression following trauma: understanding comorbidity. Am I Psychiatry. 2004;161 (8): 1390-1396. doi: 10.1176/appi.ajp.161.8.1390.

5. Kim JJ, Diamond DM. The stressed hippocampus, synaptic plasticity and lost memories. Nat Rev Neurosci.2002; 3(6): 453-462. doi: 10.1038/nrn849.

6. Duman RS, Aghajanian GK. Synaptic dysfunction in depression: potential therapeutic targets. Science. 2012; 338 (6103): 68-72. doi: 10.1126/science.1222939.

7. Jing L, Duan TT, Tian M, et al. Despair-associated memory requires a slow-onset CA1 long-term potentiationwith unique underlying mechanisms. Sci Rep.2015; 5: 15000. doi: $10.1038 /$ srep15000.

8. Sun P, Wang F, Wang L, et al. Increase in cortical pyramidal cell excitability accompanies depression-like behavior in mice: a transcranial magnetic stimulation study. J Neurosci; 2011; 31 (45): 16464 - 16472. doi: 10.1523/ 
INEUROSCI.1542-11.2011.

9. Bienenstock EL, Cooper LN, Munro PW. Theory for the development ofneuron selectivity: orientation specificity and binocular interaction in visualcortex. J Neurosci.1982; 2 (1): 32-48. doi: 10.1523/JNEUROSCI.02-01-00032.1982.

10. Bergstrom HC, McDonald CG, Dey S, et al. The structure of Pavlovian fear conditioning in the amygdala. Brain StructFunct. 2013; 218 (6): 1569-1589. doi: 10.1007/s00429-012 -0478-2.

11. Bergstrom HC. The neurocircuitry of remote cued fear memory. NeurosciBiobehav Rev. 2016.71: 409-417. doi: 10.1016/j.neubiorev.2016.09.028.

12. Kitamura T, Ogawa SK, Roy DS. et al. Engrams and circuits crucial for systems consolidation of memory. Science. 2017; 356 (6333): 73-78. doi: 10.1126/science.aam6808.

13. Gale GD, Anagnostaras SG, Godsil BP, et al.Role of the basolateral amygdala in the storage of fearmemories across the adult lifetime of rats. J Neurosci.2004;24 (15): 38103825. doi: 10.1523/INEUROSCI.4100-03.2004.

14. Lee JL. Reconsolidation: maintaining memory relevance. Trends Neurosci. 2009; 32(8): 413-420. doi: 10.1016/j. tins.2009.05.002.

15. Lee JL, Everitt BJ, Thomas KL. Independent cellular processes for hippocampal memory consolidation and reconsolidation. Science. 2004; 304 (5672): 839-843. doi: $10.1126 /$ science. 1095760

16. Debiec J, LeDoux JE, Nader K.Cellular and systems reconsolidation in the hippocampus. Neuron. 2002; 36 (3): 527538. doi: 10.1016/s0896-6273(02)01001-2.

17. Григорьян ГА, Маркевич ВА. Консолидация, реактивация и реконсолидация памяти. Журнал Высш. Нервн. Деят. 2014; 64 (2): 123-136. doi: 10.7868/ S0044467714020087

18. BaileyCH., KandelER., HarrisKM. Structural components of synaptic plasticity and memory consolidation. Cold Spring Harbor Perspec Bio. 2015; 7 (7): ArticleID a021758. doi: 10.1101/cshperspect.a021758.

19. BourneJN, HarrisKM. Balancing structure andfunction at hippocampal dendritic spines, Ann Rev Neurosci. 2008; 31: 47-67. doi: 10.1146/annurev.neuro.31.060407.125646.

20. Nakayama D, Hashikawa-Yamasaki Y, Ikegaya Y, et al. Late Arc/Arg3.1 expression in the basolateral amygdala is essential for persistence of newly-acquired and reactivated contextual fear memories. Sci Rep. 2016; 6: 21007. doi: 10.1038/srep21007.

21. Bingol B, Wang CF, Arnott D, et al. AutophosphorylatedCaMKII-alpha acts as a scaffold to recruit proteasomes to dendritic spines. Cell. 2010;140 (4):567-578. doi: 10.1016/j. cell.2010.01.024

22. Lee SH, Choi JH, Lee N, et al. Synaptic protein degradation underlies destabilization of retrieved fear memory. Science. 2008;319 (5867):1253-1256.doi: 10.1126/science. 1150541.

23. Graff J, Josef NF, Horn ME, et al.Epigenetic priming of memory updating during reconsolidation to attenuate remote fear memories. Cell. 2014;156 (1-2):261-276.doi: 10.1016/j.cell.2013.12.020.

24. Nakayama D, Iwata H, Teshirogi C, et al. Long-delayed expression of the immediate early gene Arc/Arg3.1 refines neuronal circuits to perpetuate fear memory. I Neurosci. 2015;35 (2):819-830.doi: 10.1523/JNEUROSCI.252514.2015.

25. Liu X, Gu QH, Duan K, Li Z, et al. NMDA receptor-dependent LTD is required for consolidation but not acquisition of fear memory. J Neurosci. 2014; 34 (26): 8741-8748. doi: 10.1523/INEUROSCI.2752-13.2014

26. Vanvossen AC, Portes MAM, Scoz-Silva R, et al. Newly acquired and reactivated contextual fear memories are more intense and prone to generalize after activation of prelimbic cortex NMDA receptors. Neurobiol Learn Mem. 2017; 137 (Jan): 154-162. . doi: 10.1016/j.nlm.2016.12.002.

27. Santini E, Quirk GJ, Porter JT. Fear conditioning and extinction differentially modify the intrinsic excitability of infralimbic neurons.J Neurosci. 2008;28(15):4028-4036. doi: 10.1523/JNEUROSCI.2623-07.2008.

28. Myers KM, Davis M.Mechanisms of fear extinc-
JNEUROSCI.1542-11.2011.

9. Bienenstock EL, Cooper LN, Munro PW. Theory for the development ofneuron selectivity: orientation specificity and binocular interaction in visualcortex. J Neurosci.1982; 2 (1): 32-48. doi: 10.1523/JNEUROSCI.02-01-00032.1982.

10. Bergstrom HC, McDonald CG, Dey S, et al. The structure of Pavlovian fear conditioning in the amygdala. Brain StructFunct. 2013; 218 (6): 1569-1589. doi: 10.1007/s00429-012 -0478-2.

11. Bergstrom HC. The neurocircuitry of remote cued fear memory. NeurosciBiobehav Rev. 2016.71: 409-417. doi: 10.1016/j.neubiorev.2016.09.028.

12. Kitamura T, Ogawa SK, Roy DS. et al. Engrams and circuits crucial for systems consolidation of memory. Science. 2017; 356 (6333): 73-78. doi: 10.1126/science.aam6808.

13. Gale GD, Anagnostaras SG, Godsil BP, et al.Role of the basolateral amygdala in the storage of fearmemories across the adult lifetime of rats. J Neurosci.2004;24 (15): 38103825. doi: 10.1523/INEUROSCI.4100-03.2004.

14. Lee JL. Reconsolidation: maintaining memory relevance. Trends Neurosci. 2009; 32(8): 413-420. doi: 10.1016/j. tins.2009.05.002.

15. Lee JL, Everitt BJ, Thomas KL. Independent cellular processes for hippocampal memory consolidation and reconsolidation. Science. 2004; 304 (5672): 839-843. doi: $10.1126 /$ science. 1095760 .

16. Debiec J, LeDoux JE, Nader K.Cellular and systems reconsolidation in the hippocampus. Neuron. 2002; 36 (3): 527538. doi: 10.1016/s0896-6273(02)01001-2.

17. Grigor'yan G. A., Markevich V. A. Consolidation, Reactivation, and Reconsolidation of Memory I.P. Pavlov Journal of Higher Nervous Activity 2014; 64(2):123-136. doi: 10.7868/S0044467714020087(in Russian)

18. BaileyCH., KandelER., HarrisKM. Structural components of synaptic plasticity and memory consolidation. Cold Spring Harbor Perspec Bio. 2015; 7 (7): ArticleID a021758. doi: 10.1101/cshperspect.a021758.

19. BourneJN, HarrisKM. Balancing structure andfunction at hippocampal dendritic spines, Ann Rev Neurosci. 2008; 31: 47-67. doi: 10.1146/annurev.neuro.31.060407.125646.

20. Nakayama D, Hashikawa-Yamasaki Y, Ikegaya Y, et al. Late Arc/Arg3.1 expression in the basolateral amygdala is essential for persistence of newly-acquired and reactivated contextual fear memories. Sci Rep. 2016; 6: 21007. doi: 10.1038/srep21007.

21. Bingol B, Wang CF, Arnott D, et al. AutophosphorylatedCaMKII-alpha acts as a scaffold to recruit proteasomes to dendritic spines. Cell. 2010;140 (4):567-578. doi: 10.1016/j. cell.2010.01.024.

22. Lee SH, Choi JH, Lee N, et al. Synaptic protein degradation underlies destabilization of retrieved fear memory. Science. 2008;319 (5867):1253-1256.doi: 10.1126/science. 1150541

23. Graff J, Josef NF, Horn ME, et al.Epigenetic priming of memory updating during reconsolidation to attenuate remote fear memories. Cell. 2014;156 (1-2):261-276.doi: 10.1016/j.cell.2013.12.020.

24. Nakayama D, Iwata $\mathrm{H}$, Teshirogi $\mathrm{C}$, et al. Long-delayed expression of the immediate early gene Arc/Arg3.1 refines neuronal circuits to perpetuate fear memory. I Neurosci. 2015;35 (2):819-830.doi: 10.1523/JNEUROSCI.252514.2015 .

25. Liu X, Gu OH, Duan K, Li Z, et al. NMDA receptor-dependent LTD is required for consolidation but not acquisition of fear memory. J Neurosci. 2014; 34 (26): 8741-8748. doi: 10.1523/JNEUROSCI.2752-13.2014

26. Vanvossen AC, Portes MAM, Scoz-Silva R, et al. Newly acquired and reactivated contextual fear memories are more intense and prone to generalize after activation of prelimbic cortex NMDA receptors. Neurobiol Learn Mem. 2017; 137 (Jan): 154-162. . doi: 10.1016/j.nlm.2016.12.002.

27. Santini E, Quirk GJ, Porter JT. Fear conditioning and extinction differentially modify the intrinsic excitability of infralimbic neurons.J Neurosci. 2008;28(15):4028-4036. doi: 10.1523/JNEUROSCI.2623-07.2008.

28. Myers KM, Davis M.Mechanisms of fear extinc- 
tion. Mol Psychiatry. 2007;12 (2):120-50. doi: 10.1038/ sj.mp.4001939.

29. Bender CL, Giachero M, Comas-Mutis R, et al. Stress influences the dynamics of hippocampal structural remodeling associated with fear memory extinction. Neurobiol Learn Mem. 2018; 155 (Nov):412-421. doi: 10.1016/j. nlm.2018.09.002.

30. Jasnow AM, Cullen PK, Riccio DC. Remembering another aspect of forgetting. Front Psychol. 2012; 3 (1): 175. doi: 10.3389/fpsyg.2012.00175.

31. Zhou H, Xiong G-J, Jing L, et al. The interhemispheric CA1 circuit governs rapid generalisation but not fear memory. Nat Commun. 2017; 8: 2190. doi: 10.1038/s41467-017 -02315-4.

32. Pollack GA, Bezek JL, Lee SH, et al. Cued fear memory generalization increases over time. Learn Mem. 2018; 25 (7): 298-308. doi: 10.1101/lm.047555.118.

33. Lopresto D, Schipper P, Homberg JR. Neural circuits and mechanisms involved in fear generalization: implications for the pathophysiology and treatment of posttraumatic stress disorder. NeurosciBiobehav Rev. 2016;60: 31-42. doi: 10.1016/j.neubiorev.2015.10.009.

34. Norrholm SD, Jovanovic T, Briscione MA, et al. Generalization of fear-potentiated startle in the presence of auditory cues: a parametric analysis. Front BehavNeurosci. 2014; 8: 361. doi: 10.3389/fnbeh.2014.00361.

35. PedrazaLK, Sierra RO, Giachero M, et al. Chronic fluoxetine prevents fear memory

generalization and enhances subsequent extinction by remodeling hippocampal dendritic spines and slowing down systems consolidation. Transl Psychiatry. 2019; 9: 53. doi: 10.1038/-s41398-019-0371-3.

36. Restivo L, Vetere G, Bontempi B, et al. The formation of recent and remote memory is associated with time-dependent formation of dendritic spines in the hippocampus and anterior cingulate cortex. J Neurosci. 2009;29 (25): 8206-8214. doi: 10.1523/JNEUROSCI.0966-09.2009.

37. Einarsson EÖ, Pors J, Nader K. Systems reconsolidation reveals a selective role for the anterior cingulate cortex in generalized contextual fear memory expression. Neuropsychopharmacol. 2015; 40 (2): 480-487. doi: 10.1038/ npp.2014.197.

38. Pedraza LK, Sierra RO, Boos FZ, et al. The dynamic nature of systems consolidation: stress during learning as a switch guiding the rate of the hippocampal dependency andmemory quality. Hippocampus. 2016; 26 (4): 362-371. doi: 10.1002/hipo.22527.

39. Bessa JM, Ferreira D, Melo I, et al. The mood-improving actions of antidepressants do not depend on neurogenesis but are associated with neuronal remodeling. MolPsychiatry. 2009; 14 (8): 764-773.doi: 10.1038/mp.2008.119.

40. Ritov G, Boltyansky B, Richter-Levin G. A novel approach to PTSDmodeling in rats reveals alternating patterns of limbic activity in differenttypes of stress reaction. MolPsychiatry.2016;21 (5): 630-641. doi: 10.1038/ mp.2015.169.

41. Richter-Levin G, Xu L. How could stress lead to major depressive disorder? IBRO Reports. 2018; 4 (1): 38-43. doi: 10.1016/j.ibror.2018.04.001

42. Pizzagalli DA. Frontocingulatedysfunction in depression: toward biomarkers of treatment response. Neuropsychopharmacol. 2011; 36 (2): 183-206. doi:10.1038/ npp.2010.166.

43. Nolen-Hoeksema S, Wisco BE, Lyubomirsky S.Rethinking rumination. PerspectPsychol Sci. 2008 3: 400-424. doi: 10.1111/j.1745-6924.2008.00088.x.

44. Gotlib IH, Joormann J. Cognition and depression: current status and future directions. Ann Rev Clin Psychol. 2010; 6: 285-312. doi: 10.1146/annurev.clinpsy.121208.131305.

45. Wang G, Cheng Y, Gong M, et al. Systematic correlationbetween spine plasticity and the anxiety/depression-like phenotype induced by corticosterone in mice. NeuroReport. 2013; 24 (12) 682-687. doi: 10.1097/ WNR.0b013e32836384db.

46. Hains AB, Vu MA, Maciejewski PK, et al. Inhibition of protein kinase $\mathrm{C}$ signaling protects prefrontal cortex dendrit- tion. Mol Psychiatry. 2007;12 (2):120-50. doi: 10.1038/ sj.mp.4001939.

29. Bender CL, Giachero M, Comas-Mutis R, et al. Stress influences the dynamics of hippocampal structural remodeling associated with fear memory extinction. Neurobiol Learn Mem. 2018; 155 (Nov):412-421. doi: 10.1016/j. nlm.2018.09.002.

30. Jasnow AM, Cullen PK, Riccio DC. Remembering another aspect of forgetting. Front Psychol. 2012; 3 (1): 175. doi: 10.3389/fpsyg.2012.00175.

31. Zhou H, Xiong G-I, Jing L, et al. The interhemispheric CA1 circuit governs rapid generalisation but not fear memory. Nat Commun. 2017; 8: 2190. doi: 10.1038/s41467-017 -02315-4.

32. Pollack GA, Bezek JL, Lee SH, et al. Cued fear memory generalization increases over time. Learn Mem. 2018; 25 (7): 298-308. doi: 10.1101/lm.047555.118.

33. Lopresto D, Schipper P, Homberg JR. Neural circuits and mechanisms involved in fear generalization: implications for the pathophysiology and treatment of posttraumatic stress disorder. NeurosciBiobehav Rev. 2016;60: 31-42. doi: 10.1016/j.neubiorev.2015.10.009.

34. Norrholm SD, Jovanovic T, Briscione MA, et al. Generalization of fear-potentiated startle in the presence of auditory cues: a parametric analysis. Front BehavNeurosci. 2014; 8: 361. doi: 10.3389/fnbeh.2014.00361.

35. PedrazaLK, Sierra RO, Giachero M, et al. Chronic fluoxetine prevents fear memory

generalization and enhances subsequent extinction by remodeling hippocampal dendritic spines and slowing down systems consolidation. Transl Psychiatry. 2019; 9: 53. doi: 10.1038/-s41398-019-0371-3.

36. Restivo L, Vetere G, Bontempi B, et al. The formation of recent and remote memory is associated with time-dependent formation of dendritic spines in the hippocampus and anterior cingulate cortex. J Neurosci. 2009;29 (25): 8206-8214. doi: 10.1523/JNEUROSCI.0966-09.2009.

37. Einarsson EÖ, Pors J, Nader K. Systems reconsolidation reveals a selective role for the anterior cingulate cortex in generalized contextual fear memory expression. Neuropsychopharmacol. 2015; 40 (2): 480-487. doi: 10.1038/ npp.2014.197.

38. Pedraza LK, Sierra RO, Boos FZ, et al. The dynamic nature of systems consolidation: stress during learning as a switch guiding the rate of the hippocampal dependency andmemory quality. Hippocampus. 2016; 26 (4): 362-371. doi: 10.1002/hipo.22527.

39. Bessa JM, Ferreira D, Melo I, et al. The mood-improving actions of antidepressants do not depend on neurogenesis but are associated with neuronal remodeling. MolPsychiatry. 2009; 14 (8): 764-773.doi: 10.1038/mp.2008.119.

40. Ritov G, Boltyansky B, Richter-Levin G. A novel approach to PTSDmodeling in rats reveals alternating patterns of limbic activity in differenttypes of stress reaction. MolPsychiatry.2016;21 (5): 630-641. doi: 10.1038/ mp.2015.169.

41. Richter-Levin G, Xu L. How could stress lead to major depressive disorder? IBRO Reports. 2018; 4 (1): 38-43. doi: 10.1016/j.ibror.2018.04.001

42. Pizzagalli DA. Frontocingulatedysfunction in depression: toward biomarkers of treatment response. Neuropsychopharmacol. 2011; 36 (2): 183-206. doi:10.1038/ npp.2010.166.

43. Nolen-Hoeksema S, Wisco BE, Lyubomirsky S.Rethinking rumination. PerspectPsychol Sci. 2008 3: 400-424. doi: 10.1111/j.1745-6924.2008.00088.x.

44. Gotlib IH, Joormann J. Cognition and depression: current status and future directions. Ann Rev Clin Psychol. 2010; 6: 285-312. doi: 10.1146/annurev.clinpsy.121208.131305.

45. Wang G, Cheng Y, Gong M, et al. Systematic correlationbetween spine plasticity and the anxiety/depression-like phenotype induced by corticosterone in mice. NeuroReport. 2013; 24 (12) 682-687. doi: 10.1097/ WNR.0b013e32836384db.

46. Hains AB, Vu MA, Maciejewski PK, et al. Inhibition of protein kinase $C$ signaling protects prefrontal cortex dendrit- 
ic spines and cognition from the effects of chronic stress," Proc

Nat AcadSciUSA. 2009;106, (42): 17957-17962. doi: 10.1073/ pnas.0908563106.

47. Zanos P, Moaddel R, Morris PJ, et al.. NMDAR inhibitionindependent antidepressant actions of ketamine metabolites. Nature. 2016; 533 (7604): 481-486. doi: 10.1038/nature 17998.

48. Li HB, Mao RR, Zhang JC, et al.Antistress effect ofTRPV1 channel on synaptic plasticity and spatial memory. Biol. Psychiatry. 2008; 64 (4): 286-292. doi: 10.1016/j. biopsych.2008.02.020.

49. Mayberg HS. Targeted electrode-based modulation of neural circuits for depression. J Clin Invest. 2017; 119 (4): 717-725. doi:10.1172/JCI38454.

50. Duan TT., Tan JW, Yuan Q, et al. Acute ketamine-induces hippocampal synaptic depression and spatial memory impairmentthrough dopamine D1/D5 receptors. Psychopharmacology (Berl). 2013; 228 (3): 451-461. doi: 10.1007/ s00213-013-3048-2.

51. Zhang K, Xu T, Yuan Z, et al. Essential roles of AMPA receptor GluA1 phosphorylation and presynaptic $\mathrm{HCN}$ channels in fast-acting antidepressant responses of ketamine. Sci Signal.2017; 9(458): ra123. doi:10.1126/scisignal.aai7884.

52. Abramets II, KuznetsovYuV, Evdokimov DV, Zayka TO. Piracetam potentiates neuronal and behavioral effects of ketamine. Research Results in Pharmacology. 2019; 5(3): $1-7$.

doi 10.3897/rrpharmacology.5.35530

53. Miller OH, Yang L, Wang C-C, et al. GluN2B-containing NMDA receptors regulate depression-like behavior and are critical for rapid antidepressant action of ketamine. eLife. 2014; 3: e03581. doi: 10.7554/eLife.03581.001.

54. Nabavi S, Fox R, Proulx CD, et al. Engineering a memory with LTD and LTP. Nature. 2014; 511 (7509): 348-352. doi: $10.1038 /$ nature 13294.

55. Gerhard D M, Wohleb ES, Duman RS. Emerging treatment mechanisms for depression: focus on glutamate and synaptic plasticity. Drug Discov Today. 2016; 21 (3): 454-464. doi: 10.1016/j.drudis.2016.01.016.

56. Li N, Lee B, Liu RJ, et al. mTOR-dependent synapse formation underlies the rapid antidepressant effects of NMDA antagonists. Science. 2010; 329 (5994): 959-964. doi: 10.1126/science.1190287.

57. Autry AE, Adachi M, Nosyreva E, et al. NMDA receptor blockade at rest triggers rapid behavioural antidepressant responses. Nature. 2011; 475 (7354):91-95. doi: 10.1038/ nature 10130. ic spines and cognition from the effects of chronic stress," Proc

Nat AcadSciUSA. 2009;106, (42): 17957-17962. doi: 10.1073/ pnas.0908563106.

47. Zanos P, Moaddel R, Morris PJ, et al.. NMDAR inhibitionindependent antidepressant actions of ketamine metabolites. Nature. 2016; 533 (7604): 481-486. doi: 10.1038/nature 17998.

48. Li HB, Mao RR, Zhang JC, et al.Antistress effect ofTRPV1 channel on synaptic plasticity and spatial memory. Biol. Psychiatry. 2008; 64 (4): 286-292. doi: 10.1016/j. biopsych.2008.02.020.

49. Mayberg HS. Targeted electrode-based modulation of neural circuits for depression. J Clin Invest. 2017; 119 (4): 717-725. doi:10.1172/JCI38454.

50. Duan TT., Tan JW, Yuan Q, et al. Acute ketamine-induces hippocampal synaptic depression and spatial memory impairmentthrough dopamine D1/D5 receptors. Psychopharmacology (Berl). 2013; 228 (3): 451-461. doi: 10.1007/ s00213-013-3048-2.

51. Zhang K, Xu T, Yuan Z, et al. Essential roles of AMPA receptor GluA1 phosphorylation and presynaptic HCN channels in fast-acting antidepressant responses of ketamine. Sci Signal.2017; 9(458): ra123. doi:10.1126/scisignal.aai7884.

52. Abramets II, KuznetsovYuV, Evdokimov DV, Zayka TO. Piracetam potentiates neuronal and behavioral effects of ketamine. Research Results in Pharmacology. 2019; 5(3): $1-7$.

doi 10.3897/rrpharmacology.5.35530

53. Miller OH, Yang L, Wang C-C, et al. GluN2B-containing NMDA receptors regulate depression-like behavior and are critical for rapid antidepressant action of ketamine. eLife. 2014; 3: e03581. doi: 10.7554/eLife.03581.001.

54. Nabavi S, Fox R, Proulx CD, et al. Engineering a memory with LTD and LTP. Nature. 2014; 511 (7509): 348-352. doi: 10.1038 /nature13294.

55. Gerhard D M, Wohleb ES, Duman RS. Emerging treatment mechanisms for depression: focus on glutamate and synaptic plasticity. Drug Discov Today. 2016; 21 (3): 454-464. doi: 10.1016/j.drudis.2016.01.016.

56. Li N, Lee B, Liu RJ, et al. mTOR-dependent synapse formation underlies the rapid antidepressant effects of NMDA antagonists. Science. 2010; 329 (5994): 959-964. doi: $10.1126 /$ science. 1190287.

57. Autry AE, Adachi M, Nosyreva E, et al. NMDA receptor blockade at rest triggers rapid behavioural antidepressant responses. Nature. 2011; 475 (7354):91-95. doi: 10.1038/ nature 10130 . 